\title{
ESCALA DE COMA DE GLASGOW MODIFICADA PARA PACIENTES SURDOS E AFÁSICOS
}

\section{ARTIGO ORIGINAL}

VARELA-BARCA, Francisco Napoleão Tulio ${ }^{1}$

VARELA-BARCA, Francisco Napoleão Tulio. Escala de coma de Glasgow modificada para pacientes surdos e afásicos. Revista Científica Multidisciplinar Núcleo do Conhecimento. Ano 05, Ed. 01, Vol. 10, pp. 96-101. Janeiro de 2020. ISSN: 2448-0959,

Link

de acesso:

https://www.nucleodoconhecimento.com.br/saude/coma-de-glasgow, DOI: 10.32749/nucleodoconhecimento.com.br/saude/coma-de-glasgow

\section{RESUMO}

Será apresentado, neste texto, uma pequena adaptação da Escala de Coma de Glasgow que serve para surdos e pacientes afásicos. Foram feitas observações a partir de dados coletados na literatura sobre o assunto. Nada foi encontrado a respeito da adaptação da escala para pacientes surdos e afásicos. Coletou-se os dados a partir das bases para selecionar os artigos que abrangiam a temática. Como surdos e afásicos não apresentam resposta verbal adequada em nenhum momento, torna-se necessário colocar a análise da resposta verbal sob a forma de resposta de expressão gestual, pois, dessa forma, torna-se mais completa a análise da Escala de Coma de Glasgow com adaptação para surdos. O presente estudo não é rígido, ou seja, é passível de mudanças ulteriores.

Palavras-chave: Escala de Coma de Glasgow, surdos, afásicos.

\footnotetext{
${ }^{1}$ Doutor em Ciências da Saúde, Diplom Biologe, Especialização em Gastroenterologia, Clínica Médica, Medicina da Família e da Comunidade, Graduação em Ciências Biológicas e Medicina.
}

RC: 44572

Disponível em: https://www.nucleodoconhecimento.com.br/saude/coma-de-glasgow 


\section{INTRODUÇÃO}

A Escala de Coma de Glasgow (ECG) já existe há décadas (publicada pela primeira vez em 1974 por Graham Teasdale e Bryan J. Jennet na Lancet) e vem sofrendo modificações e adaptações ao longo de sua existência, como, por exemplo, as adaptações para crianças e trauma (Tabela 1) (TEASDALE; JENNET, 1974; JANNETT; BOND, 1975;).

Tabela 1 - Escala de Coma de Glasgow em Adultos

\begin{tabular}{|l|l|}
\hline Abertura Ocular & Pontuação \\
\hline Espontâneo & 4 \\
\hline Ao estímulo verbal & 3 \\
\hline À pressão & 2 \\
\hline Nenhuma & 1 \\
\hline Resposta Verbal & Pontuação \\
\hline Orientado & 5 \\
\hline Confuso & 4 \\
\hline Palavras & 3 \\
\hline Sons & 2 \\
\hline Nenhuma & 1 \\
\hline Resposta Motora & Pontuação \\
\hline Obedece a comandos & 6 \\
\hline Localiza & 5 \\
\hline Flexão normal & 4 \\
\hline Flexão anormal & 3 \\
\hline Extensão & 2 \\
\hline Nenhum & 1 \\
\hline
\end{tabular}

A ECG serve, basicamente, para a avaliação do quadro neurológico de pacientes vítimas de distúrbios que agravam o funcionamento do sistema nervoso central

RC: 44572

Disponível em: https://www.nucleodoconhecimento.com.br/saude/coma-de-glasgow 
(avaliando, dessa forma, a profundidade e o quadro clínico do coma). Dentre estes quadros estão: traumas cranianos, acidentes vasculares cerebrais, coma alcoólico e diabético, dentre outros. Durante muito tempo a ECG tem sido utilizada para todos os tipos de pacientes, porém há negligência dos quadros de pacientes em que a avaliação não é possível. Normalmente, é recomendado o uso do termo impossibilitado de avaliação (NT) quando um determinado item não é avaliado.

Também é recomendado, nos casos de traumas, a avaliação pela ECG e acrescenta-se a letra $T$ ao final da avaliação junto com a pontuação. Tal notificação tem o intuito de determinar se o paciente é uma vítima de trauma. Aqui, neste trabalho, pretende-se preencher uma lacuna já discutida por muitas pessoas que se depararam com o quadro de atendimento de pessoas surdas ou ainda pessoas afásicas (que não conseguem emitir sons como sequela de AVC prévio) que dominam a linguagem de sinais. Vale a pena ressaltar que, atualmente, não existe mais a qualificação de surdo-mudo e sim de pessoas surdas e que não apresentam resposta verbal por não saberem como reproduzir os sons (MOORE; LEVITAN, 2003).

\section{MÉTODO}

Foram feitas observações e procuras na literatura científica sobre o assunto. Considerou-se alguns descritores como Escala de Coma de Glasgow, Suporte Básico de Vida, Atendimento de urgência a pacientes surdos, entretanto nada relevante par o estudo foi encontrado. Ou seja, nada a respeito da adaptação da escala para surdos foi encontrado em artigos científicos publicados em bases de dados ocidentais (língua inglesa, francesa, espanhola, portuguesa). Os materiais coletados para a pesquisa foram obtidos na Scielo, Lilacs e NCBI (além de uma procura geral na rede mundial de computadores a partir do Google). Observações também foram feitas em buscas aleatórias junto a rede mundial de computadores sobre relatos de atendimentos de pacientes surdos e o uso da Escala de Coma de

RC: 44572

Disponível em: https://www.nucleodoconhecimento.com.br/saude/coma-de-glasgow 
Glasgow, mas não foram encontradas publicações oficiais, apesar dos relatos tratarem sobre a grande dificuldade de uso da Escala para tais pacientes.

\section{RESULTADO}

Após a análise de diversas situações possíveis relacionadas aos pacientes surdos e afásicos, sugere-se a publicação da Escala de Coma de Glasgow, de acordo com a tabela 2. Tal tabela foi elaborada, principalmente, para verificar como o paciente é capaz de se comunicar por meio da linguagem de sinais padronizada de forma oficial no país em questão. Há dados, ainda, sobre a linguagem coloquial no âmbito familiar e social que fogem dos padrões tradicionais. Também foi levada em consideração o fato de que a abertura ocular e os comandos sobre a motricidade não teriam qualquer impacto sobre ECG, como já é praticada atualmente.

Tabela 2 - Modificações Didáticas sugeridas para aplicação da Escala de Coma de Glasgow em Surdos e Afásicos

\begin{tabular}{|l|l|}
\hline Resposta Comunicativa & Valor Atribuído \\
\hline Comunicação de forma orientada & 5 \\
\hline $\begin{array}{l}\text { Comunicação de forma confusa } \\
\text { Palavras inapropriadas/expressões } \\
\text { gestuais inapropriadas }\end{array}$ & 3 \\
\hline $\begin{array}{l}\text { Sons inapropriados/expressões gestuais } \\
\text { incompletas }\end{array}$ & 2 \\
\hline Nenhuma resposta comunicativa & 1 \\
\hline
\end{tabular}

Fonte: Elaborada pelo autor (2020)

\section{DISCUSSÃO}

A inclusão de minorias no ambiente social humano tem sido incentivada por várias nações. Inclusive, por vezes, há grande impacto no cotidiano, pois a temática foi um

RC: 44572

Disponível em: https://www.nucleodoconhecimento.com.br/saude/coma-de-glasgow 
dos temas de redação em concursos públicos de grande repercussão internacional (MORENO, 2017). O Brasil possui educadores expressivos que discutem sobre uma política nacional de inclusão (MORENO, 2017; BRASIL, 1994). No que se diz respeito ao tratamento de surdos e até mesmo de paciente afásicos (por lesões neurológicas prévias e que conheçam a linguagem de sinais) em unidades de emergência, observa-se, na rede mundial de computadores, alguns relatos isolados de atendimentos destes pacientes bem como a dificuldade de uso da Escala de Coma de Glasgow para essas pessoas, porém não há publicações oficiais (PONTE; FEDOSSE, 2016).

Como pacientes surdos e afásicos não possuem a capacidade de reproduzir sons verbais, sugere-se que nas tabelas voltadas à Escala de Coma de Glasgo seja acrescentado na seção de reprodução verbal o termo Expressão Gestual (ver tabela 2). Além disso, no tocante ao tipo de resposta, seria mais adequado definir esta como comunicativa ao invés de resposta verbal. Para os demais parâmetros, cabe, à equipe, conseguir dialogar com os pacientes, ou seja, teoricamente não há necessidade de mudanças da seção de resposta ocular ou motora. Fica subentendido que qualquer resposta comunicativa representa uma resposta motora com valor 6, porém a recíproca não é verdadeira, uma vez que lesões que causem paraplegia podem impedir expressões gestuais. Nessas situações, torna-se necessária a análise clínico-neurológico de todos os segmentos e dermátomos.

\section{CONCLUSÃO}

A partir do exposto, percebe-se que novos estudos já estão em andamento para comprovar a aplicação dessa tabela bem como para verificar as suas limitações, o que gera reflexões e possíveis mudanças no atendimento médico. Programas de aprendizagem de línguas de sinais também terão papel fundamental para um melhor atendimento desses pacientes por parte dos profissionais de saúde. Espera-se, com este estudo, que novos trabalhos possam surgir, indagando sobre outras possíveis

RC: 44572

Disponível em: https://www.nucleodoconhecimento.com.br/saude/coma-de-glasgow 
mudanças em sistemas avaliativos similares de vítimas e que os mesmos possam ser colocados em prática no atendimento diários a essas pessoas.

\section{REFERÊNCIAS}

BRASIL. Ministério da Educação. Secretaria de Educação Especial. Política Nacional de Educação Especial. Brasília: MEC/SEESP, 1994.

JENNETT, B; BOND, M. Assessment of outcome after severe brain damage: a practical scale. The Lancet, v. 305, n. 7905, p. 480-484, 1975.

MOORE, M. S.; LEVITAN, L. For Hearing People Only, Answers to Some of the Most Commonly Asked Questions About the Deaf Community, its Culture, and the "Deaf Reality". New York: Deaf Life Press, 2003.

MORENO, A. C. Tema da Redação do ENEM 2017 fala sobre a educação de surdos no $\quad$ Brasil. 2017.2 Disponível em: https://g1.globo.com/educacao/enem/2017/noticia/tema-da-redacao-do-enem-2017fala-sobre-a-educacao-de-surdos-no-brasil.ghtml. Acesso em: 27 jan. 2020.

PONTE, A. S; FEDOSSE, E. Lesão Encefálica Adquirida: impacto na atividade laboral de sujeitos em idade produtiva e de seus familiares. Ciência \& Saúde Coletiva, v. 21, p. 3171-3182, 2016.

TEASDALE, G; JENNETT, B. Assessment of coma and impaired consciousness: a practical scale. The Lancet, v. 304, n. 7872, p. 81-84, 1974.

Enviado: Novembro, 2019.

Aprovado: Janeiro, 2020.

RC: 44572

Disponível em: https://www.nucleodoconhecimento.com.br/saude/coma-de-glasgow 